\title{
Expiratory flow limitation in intensive care: prevalence and risk factors
}

\author{
Carlo Alberto Volta ${ }^{1}$, Francesca Dalla Corte ${ }^{1}$, Riccardo Ragazzi ${ }^{1}$, Elisabetta Marangoni ${ }^{1}$, Alberto Fogagnolo ${ }^{1}$, \\ Gaetano Scaramuzzo ${ }^{1}$, Domenico Luca Grieco ${ }^{2}$, Valentina Alvisi', Chiara Rizzuto ${ }^{1,3}$ and Savino Spadaro ${ }^{1 *}$ (i)
}

\begin{abstract}
Background: Expiratory flow limitation (EFL) is characterised by a markedly reduced expiratory flow insensitive to the expiratory driving pressure. The presence of EFL can influence the respiratory and cardiovascular function and damage the small airways; its occurrence has been demonstrated in different diseases, such as COPD, asthma, obesity, cardiac failure, ARDS, and cystic fibrosis. Our aim was to evaluate the prevalence of EFL in patients requiring mechanical ventilation for acute respiratory failure and to determine the main clinical characteristics, the risk factors and clinical outcome associated with the presence of EFL.
\end{abstract}

Methods: Patients admitted to the intensive care unit (ICU) with an expected length of mechanical ventilation of $72 \mathrm{~h}$ were enrolled in this prospective, observational study. Patients were evaluated, within $24 \mathrm{~h}$ from ICU admission and for at least $72 \mathrm{~h}$, in terms of respiratory mechanics, presence of EFL through the PEEP test, daily fluid balance and followed for outcome measurements.

Results: Among the 121 patients enrolled, 37 (31\%) exhibited EFL upon admission. Flow-limited patients had higher BMl, history of pulmonary or heart disease, worse respiratory dyspnoea score, higher intrinsic positive endexpiratory pressure, flow and additional resistance. Over the course of the initial $72 \mathrm{~h}$ of mechanical ventilation, additional 21 patients (17\%) developed EFL. New onset EFL was associated with a more positive cumulative fluid balance at day $3(103.3 \mathrm{ml} / \mathrm{kg})$ compared to that of patients without EFL $(65.8 \mathrm{ml} / \mathrm{kg})$. Flow-limited patients had longer duration of mechanical ventilation, longer ICU length of stay and higher in-ICU mortality.

Conclusions: EFL is common among ICU patients and correlates with adverse outcomes. The major determinant for developing EFL in patients during the first 3 days of their ICU stay is a positive fluid balance. Further studies are needed to assess if a restrictive fluid therapy might be associated with a lower incidence of EFL.

Keywords: Respiratory insufficiency, Fluid therapy, Lung disease, Respiratory mechanics, Maximal expiratory flow rates, Critical care

\section{Background}

Expiratory flow limitation (EFL) is a dynamic condition in which expiratory flow has already reached its maximal value [1]. According to Mead et al. [2], once the expiratory flow is limited at a given lung volume, there is a site in the intrathoracic airways where intrabronchial and extrabronchial pressure are equal, the so-called equal pressure point (EPP) [3]. Airways downstream of the EPP would be compressed, the diameter markedly

\footnotetext{
* Correspondence: savinospadaro@gmail.com

${ }^{1}$ Department of Morphology, Surgery and Experimental Medicine, Azienda Ospedaliera-Universitaria Arcispedale Sant'Anna, University of Ferrara, Via Aldo Moro, 8, 44124 Ferrara, Italy

Full list of author information is available at the end of the article
}

reduced, with the expiratory flow becoming insensitive to increases of expiratory driving pressure or to the contraction of the expiratory muscles $[1,4-7]$.

Clinically, EFL was demonstrated in patients with chronic obstructive pulmonary disease (COPD) [4, 8], acute respiratory distress syndrome (ARDS) [9, 10], acute and chronic heart failure [11, 12], cystic fibrosis [13], spinal cord injury [14] and obesity [15]. Recently, EFL has been described in patients undergoing general anaesthesia for major abdominal surgery, and its presence was the best predictors of postoperative pulmonary complications [16].

(C) The Author(s). 2019 Open Access This article is distributed under the terms of the Creative Commons Attribution 4.0 International License (http://creativecommons.org/licenses/by/4.0/), which permits unrestricted use, distribution, and reproduction in any medium, provided you give appropriate credit to the original author(s) and the source, provide a link to the Creative Commons license, and indicate if changes were made. The Creative Commons Public Domain Dedication waiver (http://creativecommons.org/publicdomain/zero/1.0/) applies to the data made available in this article, unless otherwise stated. 
The mechanisms leading to EFL can vary among different pathologies. COPD patients may develop EFL because of increased expiratory resistance [17] that tend to reduce the transmural pressure (i.e. the difference between the pressure inside and outside the airways), leading to the development of the EPP. Incomplete lung emptying is frequently associated with dynamic lung hyperinflation with the generation of intrinsic positive end-expiratory pressure (PEEPi) [18]. The latter can have several adverse effects on haemodynamic (i.e. cardiac output depression, increased pulmonary vessel resistance), respiratory muscle function (i.e. altered length-tension characteristics of the diaphragm, increased work of breathing) and patient-ventilator interaction (i.e. patient-ventilator asynchrony). On the other hand, patients with ARDS [19] or those undergoing general anaesthesia [20] can experience a reduction of functional residual capacity (FRC) able both to increase the expiratory resistance and to favour the collapse of the small airways. The ensuing inspiration re-open those airways, and repetitive opening and closure of small airways has been shown to induce histological damage of small airways probably due to the development of high shear forces [21, 22]. This should elicit an inflammatory response and increase the risk of low lung volume injury $[23,24]$.

Although EFL seems to represent a relevant pathological condition, surprisingly, only few studies evaluated the prevalence of EFL in critically ill patients. Alvisi et al. [8] demonstrated that almost every COPD patient (93\%) is flow limited at intensive care unit (ICU) admission for an acute and chronic respiratory failure, while Koutsoukou et al. [9] found that EFL might be common in patients with ARDS. However, both studies enrolled a small number of selected patients so that it is difficult to derive conclusions on the clinical relevance of EFL and its determinants.

The primary aim of the present study is to evaluate the prevalence of EFL in ICU patients requiring mechanical ventilation for acute respiratory failure, and to determine the main clinical characteristics and risk factors associated with the presence of EFL. Secondly, we explored the possible impact of the presence of EFL on patients' clinical outcome.

\section{Methods}

\section{Design, setting and patients}

We performed a prospective, observational study conducted in the general ICU of the S. Anna University Hospital, Ferrara, Italy. The study was approved by the ethics committee of our institution (Azienda OspedalieroUniversitaria Ferrara Ethic Committee, protocol number: 74/2016). Informed consent was obtained from each patient or next of kin. Patients were recruited over a 12month period between April 2016 and April 2017.
We screened and included all consecutive patients admitted to the ICU older than 18 years with an acute respiratory failure and with an expected length of mechanical ventilation of $72 \mathrm{~h}$ or more, as judged by the physician in charge. Exclusion criteria were (1) pregnancy, (2) haemodynamic instability (i.e. heart rate $\geq 120$ beats/min or cardiac arrhythmia; systolic blood pressure $<90$ or vasopressor use, i.e. dopamine or dobutamine $\geq 5 \mu \mathrm{g} / \mathrm{kg} / \mathrm{min}$ or noradrenaline $\geq 0.1 \mu \mathrm{g} / \mathrm{kg} / \mathrm{min}$ ), (3) presence of laparostomy and (4) active air leakage (i.e. pneumothorax or presence of thoracic drainage) (Additional file 1).

The observational period started within $24 \mathrm{~h}$ from admission to ICU and continued for at least $72 \mathrm{~h}$. Patients were followed for outcome assessment until hospital discharge.

\section{Determination of EFL and respiratory variables}

All measurements were performed by three investigators (FDC, CR, EM) equally expert in respiratory mechanics and data collection. Patients were studied in a semirecumbent position, with a head of bed angle of $30^{\circ}$.

The presence of EFL was determined by the PEEP test. The latter is based on a sudden decrease of PEEP from 3 to $0 \mathrm{cmH}_{2} \mathrm{O}$ at the end of inspiration in order to increase the expiratory driving pressure and establish whether or not the expiratory flow increases. If the expiratory flow increases after subtraction of PEEP, then the patient is classified as not flow limited. On the contrary, if the expiratory flow does not increase after subtraction of PEEP, the patient is classified as having EFL. This approach requires a specific manoeuvre to show two different flow-volume loops in the same display, and it is available on all modern ventilators. The flowvolume curve with $3 \mathrm{cmH}_{2} \mathrm{O}$ of PEEP is used as a reference and fixed on the screen. The flow-volume curve of the ensuing breath in which PEEP is reduced to $0 \mathrm{cmH}_{2} \mathrm{O}$ is superimposed to the previous one in order to determine if the two flow-volume curves overlap (i.e. the expiratory flow does not increase), or the flowvolume curve at ZEEP exhibit an increase of the expiratory flow (patient not flow limited) (Additional file 2). The accuracy and the reproducibility of the PEEP test have been compared to the Negative Expiratory Pressure (NEP) test and validated previously [20]. Further, the same PEEP test was used to determine the value of PEEP able to eliminate the presence of EFL, the so-called PEEP-EFL. The latter was calculated as the minimal value of PEEP that, according to the flow-volume curve, allows the expiratory flow to increase during tidal expiration (Fig. 1). This was obtained by an incremental PEEP trial.

Respiratory mechanics were performed at zero-PEEP (ZEEP) by the standard airway occlusion technique using a 5-s end-expiratory occlusion followed by a 5-s end- 

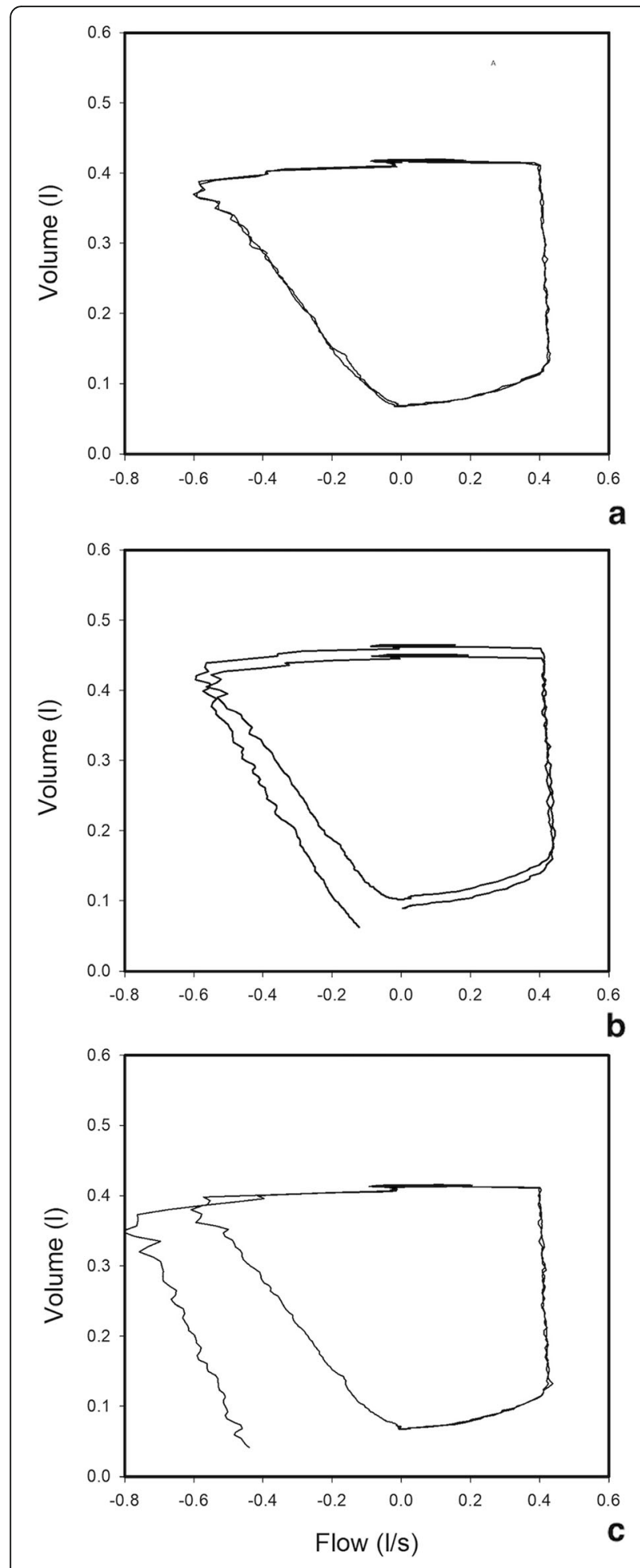

Fig. 1 Flow-volume curves of a representative patient aimed to determine the level of PEEP able to eliminate the presence of EFL (PEEP-EFL). a Until the subtraction of $4 \mathrm{cmH}_{2} \mathrm{O}$ of PEEP the expiratory flow did not increased: the patient was considered flow limited at $4 \mathrm{cmH}_{2} \mathrm{O}$ of PEEP. b Subtraction of $6 \mathrm{cmH}_{2} \mathrm{O}$ of PEEP increased the expiratory flow. c Subtraction of $8 \mathrm{cmH}_{2} \mathrm{O}$ increased the expiratory flow more than after the subtraction of $6 \mathrm{cmH}_{2} \mathrm{O}$ of PEEP. The PEEP-EFL was $5 \mathrm{cmH}_{2} \mathrm{O}$. See text for further explanation

inspiratory occlusion [20]. The flow and additional resistance as well as the static compliance of the respiratory system were computed using standard formulas [20]. During these tests, patients were deeply sedated using continuous intravenous infusion of propofol (1-2 $\mathrm{mg} / \mathrm{kg}$ ) and paralysed with a bolus of rocuronium bromide $(0.6 \mathrm{mg} / \mathrm{kg})$ and mechanically ventilated in volumecontrolled mode. Patients with COPD were studied after at least $8 \mathrm{~h}$ from the administration of albuterol. As per our clinical practice, patients without COPD were not given bronchodilators.

The severity of chronic dyspnoea was rated according to the modified dyspnoea scale proposed by the Medical Research Council (mMRC) [25].

\section{Data collection and outcome data}

The presence of EFL was determined at the ICU admission (within $12 \mathrm{~h}$ ) and daily during the first $72 \mathrm{~h}$. Data of respiratory mechanics were assessed at day 1 and at day 3 from ICU admission.

Demographics, anthropometrics, comorbidities, information and causes of hospitalisation were recorded into study-specific case report forms and database. COPD was defined according to recent ATS/ERS criteria [26], and COPD severity was assessed by the Global Initiative for COPD (GOLD) criteria [27]. Simplified Acute Physiology Score (SAPS) II and Sequential Organ Failure Assessment (SOFA) were determined during the first $24 \mathrm{~h}$ after ICU admission. The diagnosis of ARDS was based on the Berlin definition [28]. The occurrences of acute kidney injury (AKI) and septic shock were diagnosed according to international guidelines statements, Kidney Disease: Improving Global Outcomes (KDIGO) criteria [29] and surviving sepsis campaign (Sepsi-3) criteria [30], respectively.

Daily fluid balance was recorded as the algebraic sum of fluid intake and output per day, not including insensible losses, while cumulative fluid balance (CFB) was calculated as the algebraic sum of daily fluid balance during the observational period. We reported CFB as absolute number or divided by the admission weight of the patient $(\mathrm{CFB} / \mathrm{kg})$. Cumulative fluid overload (CFO) was calculated by dividing the CFB by the admission weight of each patient and was expressed as a percentage, as previously proposed [31]. We considered a CFO $\geq$ $10 \%$ as severe fluid overload. 
Outcome data such as days of mechanical ventilation, ICU and hospital length of stay and ICU and hospital mortality were retrieved from the hospital's electronic patient chart.

\section{Statistical analysis}

Data are presented as frequencies and percentages and mean \pm standard deviation or medians with 25 th to 75 th percentiles range [interquartile range], depending on the type of data and their distribution. The Shapiro-Wilk test was used to assess the assumption of normality. Categorical data were compared using the $X^{2}$ test or Fisher exact test as appropriate. Unpaired Student's $t$ tests or Mann-Whitney $U$ tests for data with normal or non-normal distribution, respectively, were used to compare continuous variables.

Friedman test was used to test differences in CFB, $\mathrm{CFB} / \mathrm{kg}$ and $\mathrm{CFO}$ within groups among three different time points $(24 \mathrm{~h}, 48 \mathrm{~h}$ and $72 \mathrm{~h}$ from ICU admission). Kruskal-Wallis test and Mann-Whitney test were used to test differences in $\mathrm{CFB}, \mathrm{CFB} / \mathrm{kg}$ and $\mathrm{CFO}$ between groups at three different time points $(24 \mathrm{~h}, 48 \mathrm{~h}$ and $72 \mathrm{~h}$ from ICU admission). Correlation between $\mathrm{CFB} / \mathrm{kg}$ and intrinsic PEEP was assessed by linear regression.

The association between the presence of EFL at admission and baseline patient characteristics was modelled using binary logistic regression analysis and reported as estimated odds ratio (OR) and relative 95\% confidence interval (CI). Patients' characteristics independently associated with the presence of EFL at ICU admission were assessed in a multivariate logistic regression model. In the same fashion, a univariate logistic approach was used to assess the association between a $\mathrm{CFO} \geq 10 \%$, the development of AKI in ICU, AHRF, ARDS or septic shock at admission and the incidence of EFL during the first $72 \mathrm{~h}$ of ICU stay.

Statistical analyses were performed using SPSS 20.0 statistical software (SPSS Inc., Chicago, IL). In all statistical analyses, a 2-tailed test was performed and the $p$ value $\leq .05$ was considered statistically significant.

\section{Results}

A total of 121 patients were enrolled, and their main characteristics at admission are shown in Table 1. The most frequent causes for ICU admission were acute hypoxaemic respiratory failure (AHRF) (43\%), sepsis (37\%), ARDS (24\%) and haemorrhagic shock (9\%). Among the 121 patients included, 28 had a diagnosis of COPD and 6 of them were admitted for an acute exacerbation of COPD.

\section{Occurrence of EFL}

Upon admission, 37/121 (31\%) patients exhibited EFL, with a median PEEP-EFL of $8 \mathrm{cmH}_{2} \mathrm{O}$ [6-10]. Among the patients having EFL at admission, 19/37 (51\%) had a diagnosis of COPD. Compared to those without EFL, flow-limited patients had a higher body mass index (BMI) $(30.7 \pm 6.8$ vs $25.3 \pm 3.9, p<0.0001)$ and worse respiratory dyspnoea score [mMRC $\geq 326 / 37$ (70\%) vs $9 /$ 84 (11\%), $p<0.0001$ ]. EFL was more frequently associated with history of heart disease $(28 / 37(76 \%)$ vs $40 / 84$ (48\%), $p=0.004)$, COPD (19/37 (51\%) vs 9/84 (11\%), $p<$ $0.0001)$ and chronic kidney disease $(11 / 37(30 \%)$ vs $10 /$ 84 (12\%), $p=0.017)$. Furthermore, the main factors independently related to EFL at ICU admission were a BMI $\geq$ $30 \mathrm{~kg} / \mathrm{m}^{2}$ (OR 3.6, 95\% CI 1.0-12.6, $p=0.049$ ), a mMRC score $\geq 3$ (OR 8.0, 95\% CI 2.3-27.1, $p=0.001$ ), a SOFA score $\geq 6$ (OR 3.6, 95\% CI 1.1-12.0, $p=0.036)$ and a medical history of COPD (OR 4.7, 95\% CI 1.5-14.4, $p=$ 0.008) (Table 2).

During the first $72 \mathrm{~h}$ of ICU stay, 21 additional patients (17\%) developed EFL. Specifically, 13 patients (11\%) became flow limited after $48 \mathrm{~h}$ and 8 (7\%) after 72 h. Their clinical characteristics are reported in Additional file 2. Of note, they exhibited a BMI similar to the one of patients without EFL and the diagnosis of COPD (Additional file 3). Finally, patients becoming flow limited during the ICU stay exhibited values of PEEP-EFL statistically lower than those with EFL at ICU admission (Additional file 4).

\section{Data of respiratory mechanics}

At the ICU admission, patients with EFL exhibited higher PEEPi $\left(7[4-10]\right.$ vs $\left.2[1-2] \mathrm{cmH}_{2} \mathrm{O}, p<0.0001\right)$, total airways resistance $(22[17-26]$ vs 16 [13-21] $\left.\mathrm{cmH}_{2} \mathrm{O} / \mathrm{l} / \mathrm{s} p<0.0001\right)$ and additional resistance (10 [614] vs 7 [5-10] $\mathrm{cmH}_{2} \mathrm{O} / \mathrm{l} / \mathrm{s}, p=0.001$ ) (Table 3). These differences remained constant during the ICU stay, being detected also at $72 \mathrm{~h}$ after ICU admission (Table 3). Of note, data of respiratory mechanics of patients developing EFL during the ICU stay were not different from those obtained in the absence of EFL (Additional file 5).

\section{Cumulative fluid balance and EFL development}

Patients who developed EFL during the first $72 \mathrm{~h}$ of ICU stay had a higher cumulative fluid balance and cumulative fluid overload compared to patients without EFL and with EFL at ICU admission. The trend of cumulative fluid accumulation is shown in Fig. 2 and in Additional file 6.

In patients developing EFL during the ICU stay, a higher cumulative fluid balance was associated with higher values of intrinsic PEEP on the day of EFL development $\left(R^{2}=0.304, p=0.010\right)$ (Fig. 3).

Moreover, a $\mathrm{CFO} \geq 10 \%$ over the first 2 and 3 days of ICU stay was associated with the development of EFL over the first 3 days of stay in ICU (OR 3.9, 95\% CI 1.4$10.9, p=0.011$ and OR $3.195 \%$ CI $1.1-8.5, p=0.030$, respectively) (Table 4). 
Table 1 Clinical and demographic characteristics of the patients at ICU admission

\begin{tabular}{|c|c|c|c|c|}
\hline Variables & Total $(n=121)$ & $\mathrm{NO}$ EFL $(n=84)$ & $\mathrm{EFL}(n=37)$ & $p$ value \\
\hline Age & $68 \pm 14$ & $67 \pm 15$ & $71 \pm 12$ & 0.181 \\
\hline Male sex, $n(\%)$ & $81(67)$ & $60(71)$ & $21(57)$ & 0.114 \\
\hline $\mathrm{BMI}, \mathrm{kg} / \mathrm{m}^{2}$ & $27.0 \pm 5.6$ & $25.3 \pm 3.9$ & $30.7 \pm 6.8$ & $<0.0001$ \\
\hline SOFA at admission & 6 [4-9] & $6[4-8]$ & $8[6-10]$ & 0.015 \\
\hline SAPSII & $42[31-48]$ & 38 [29-47] & 42 [35-53] & 0.077 \\
\hline Smoking history, $n(\%)$ & & & & 0.343 \\
\hline Current smoker & $29(24)$ & $17(20)$ & $12(32)$ & \\
\hline Former smoker & $31(26)$ & $16(25)$ & $15(26)$ & \\
\hline $\mathrm{mMRC} \geq 3$ & $35(29)$ & $9(11)$ & $26(70)$ & $<0.0001$ \\
\hline $\mathrm{NYHA} \geq 2$ & $62(51)$ & $27(32)$ & $35(95)$ & $<0.0001$ \\
\hline \multicolumn{5}{|l|}{ Comorbidities, n (\%) } \\
\hline Heart diseases & $68(56)$ & $40(48)$ & $28(76)$ & 0.004 \\
\hline Hypertension & $42(35)$ & $28(33)$ & $14(38)$ & 0.632 \\
\hline Chronic cardiac ischaemia & $43(36)$ & $22(26)$ & $21(57)$ & 0.001 \\
\hline COPD & $28(23)$ & $9(11)$ & $19(51)$ & $<0.0001$ \\
\hline OSAS & $7(6)$ & $3(4)$ & $4(11)$ & 0.116 \\
\hline CKD & $21(17)$ & $10(12)$ & $11(30)$ & 0.017 \\
\hline \multicolumn{5}{|l|}{ Reason for MV initiation, $n$ (\%) } \\
\hline AHRF & $52(43)$ & $31(37)$ & $21(57)$ & 0.042 \\
\hline Sepsis & $45(37)$ & $34(41)$ & $11(30)$ & 0.260 \\
\hline Septic shock & $28(23)$ & $21(25)$ & $7(19)$ & 0.465 \\
\hline Haemorrhagic shock & $11(9)$ & $8(10)$ & $3(8)$ & 0.803 \\
\hline Coma & $13(11)$ & $11(13)$ & $2(5)$ & 0.208 \\
\hline ARDS & $29(24)$ & $13(16)$ & $16(43)$ & 0.001 \\
\hline Mild & $7(24)$ & $3(23)$ & $4(24)$ & \\
\hline Moderate & $14(48)$ & $8(62)$ & $6(38)$ & \\
\hline Severe & $8(28)$ & $2(15)$ & $6(38)$ & \\
\hline
\end{tabular}

EFL expiratory flow limitation, BMI body mass index, SOFA Sequential Organ Failure Assessment, SAPS II Simplified Acute Physiology Score, $m$ MRC modified Medical Research Council dyspnoea scale, NYHA New York Heart Association classification, COPD chronic obstructive pulmonary disease, OSAS obstructive sleep apnoea syndrome, CKD chronic kidney disease, ICU intensive care unit, AHRF acute hypoxaemic respiratory failure, ARDS acute respiratory distress syndrome

\section{Outcomes}

Overall, patients who had EFL at admission and developed EFL over the first $72 \mathrm{~h}$ of ICU stay were ventilated for a longer time (9 [5-15] vs 7 [3-14] days, $p=0.043)$ and had a longer ICU length of stay (14 [10-19] vs 10 [6-17] days, $p=0.034)$ and higher ICU mortality (17/58 (29\%) vs 9/63 (14\%), $p=0.044$ ) compared to those without EFL.

Patients who developed EFL during the first 3 days of ICU stay were not ventilated for a longer time (8 [3-15] vs 7 [3-14] days, $p=0.448)$ and had no longer ICU length of stay (14 [8-18] vs 10 [6-17] days, $p=0.344)$ and higher ICU mortality (5/21 (24\%) vs 9/63 (14\%), $p=$ $0.310)$ compared to patients who never developed EFL.

\section{Discussion}

The main results of the present study can be summarised as follows: (1) EFL is frequent among ICU patients requiring mechanical ventilation for acute respiratory failure of different origin; (2) patients exhibiting EFL have worse parameters of respiratory mechanics and clinical outcome compared to those who did not; (3) the absence of EFL at ICU admission does not exclude its occurrence during ICU stay since part of the patients (17\%) developed EFL after ICU admission; and (4) the development of EFL during the ICU stay was strongly associated with a positive fluid balance.

The presence of EFL was previously detected in 93\% of the COPD patients at ICU admission [8], and their pathophysiological pulmonary characteristics explain why they are prone to develop EFL compared to other categories of patients. However, the presence of EFL has been previously demonstrated in other patients so that it could be hypothesised that an unknown amount of ICU patients other than COPD can exhibit EFL. This could 
Table 2 Association between baseline characteristics of patients and the presence of EFL at ICU admission according to logistic regression analysis adjusted for potential confounders

\begin{tabular}{|c|c|c|c|c|c|c|}
\hline \multirow[t]{2}{*}{ Variables } & \multicolumn{3}{|l|}{ Univariate analysis } & \multicolumn{3}{|l|}{ Multivariate analysis } \\
\hline & Crude odds ratio & $95 \% \mathrm{Cl}$ & $p$ value & Adjusted odds ratio & $95 \% \mathrm{Cl}$ & $p$ value \\
\hline \multicolumn{7}{|c|}{ BMI (ref: $<30 \mathrm{~kg} / \mathrm{m}^{2}$ ) } \\
\hline$\geq 30 \mathrm{~kg} / \mathrm{m}^{2}$ & 7.0 & $2.8-17.3$ & $<0.0001$ & 3.6 & $1.0-12.6$ & 0.049 \\
\hline \multicolumn{7}{|l|}{ mMRC (ref: <3) } \\
\hline$\geq 3$ & 19.7 & $7.3-52.8$ & $<0.0001$ & 8.0 & $2.3-27.1$ & 0.001 \\
\hline \multicolumn{7}{|l|}{ COPD (ref: absence) } \\
\hline Presence & 8.8 & $3.4-22.6$ & $<0.0001$ & 4.6 & $1.4-15.3$ & 0.008 \\
\hline \multicolumn{7}{|c|}{ Heart disease (ref: absence) } \\
\hline Presence & 3.7 & $1.6-8.3$ & 0.002 & 1.6 & $0.5-5.0$ & 0.418 \\
\hline \multicolumn{7}{|l|}{ CKD (ref: absence) } \\
\hline Presence & 3.1 & $1.2-8.2$ & 0.021 & 1.7 & $0.4-6.7$ & 0.470 \\
\hline \multicolumn{7}{|c|}{ SOFA score (ref: < 7) } \\
\hline$\geq 6$ & 3.0 & $1.2-7.3$ & 0.016 & 3.6 & $1.1-12.0$ & 0.036 \\
\hline \multicolumn{7}{|l|}{ OSAS (ref: absence) } \\
\hline Presence & 3.3 & $0.7-15.4$ & 0.134 & & & \\
\hline \multicolumn{7}{|l|}{ Age (ref: < 70) } \\
\hline$\geq 70$ & 0.9 & $0.5-2.1$ & 0.968 & & & \\
\hline \multicolumn{7}{|c|}{ Smoking history (ref: non-smoker) } \\
\hline Actual smoker & 1.8 & $0.7-4.6$ & 0.203 & & & \\
\hline Past smoker & 0.9 & $0.3-2.4$ & 0.834 & & & \\
\hline \multicolumn{7}{|l|}{ SAPS II (ref: < 41) } \\
\hline$\geq 42$ & 1.7 & $0.7-3.7$ & 0.188 & & & \\
\hline
\end{tabular}

$B M I$ body mass index, $m M R C$ modified Medical Research Council scale for dyspnoea, COPD chronic obstructive pulmonary disease, CKD chronic kidney disease, OSAS obstructive sleep apnoea syndrome, SOFA Sequential Organ Failure Assessment, SAPS Simplified Acute Physiology Score

Table 3 Data of respiratory mechanics at day 1 and day 3 after ICU admission

\begin{tabular}{|c|c|c|c|c|c|c|}
\hline \multirow[t]{2}{*}{ Variables } & \multicolumn{3}{|l|}{ Day 1} & \multicolumn{3}{|l|}{ Day 3} \\
\hline & NO EFL $(n=84)$ & $\mathrm{EFL}(n=37)$ & $p$ value & NO EFL $(n=63)$ & $\mathrm{EFL}(n=58)$ & $p$ value \\
\hline $\mathrm{Cst}, \mathrm{rs}, \mathrm{ml} / \mathrm{cmH}_{2} \mathrm{O}$ & $49[40-64]$ & $47[38-56]$ & 0.309 & 48 [39-61] & 52 [39-56] & 0.652 \\
\hline $\mathrm{Rrs}, \max , \mathrm{cmH}_{2} \mathrm{O} / \mathrm{l} / \mathrm{s}$ & 16 [13-21] & 22 [17-26] & $<0.0001$ & 17 [15-20] & $21[17-27]$ & 0.031 \\
\hline $\mathrm{Rrs}, \mathrm{min}, \mathrm{cmH}_{2} \mathrm{O} / \mathrm{l} / \mathrm{s}$ & 8 [6-12] & 9 [7-13] & 0.269 & 9 [7-13] & 9 [7-14] & 0.825 \\
\hline$\Delta \mathrm{Rrs}, \mathrm{cmH}_{2} \mathrm{O} / \mathrm{l} / \mathrm{s}$ & $7[5-10]$ & $10[6-14]$ & 0.001 & $7[5-10]$ & $11[6-14]$ & 0.008 \\
\hline $\mathrm{P} / \mathrm{F}$ ratio & 257 [177-370] & 168 [123-260] & 0.003 & 230 [170-329] & 183 [134-265] & $<0.0001$ \\
\hline PEEP $_{\mathrm{i}}, \mathrm{CmH}_{2} \mathrm{O}$ & $2[1-2]$ & 7 [4-10] & $<0.0001$ & $1[0-2]$ & $6[4-9]$ & $<0.0001$ \\
\hline PEEPappl, $\mathrm{cmH}_{2} \mathrm{O}$ & 7 [6-8] & $10[8-12]$ & $<0.0001$ & $8[6-10]$ & 10 [8-12] & $<0.0001$ \\
\hline RR, breaths/min & 15 [14-18] & 15 [14-16] & 0.839 & 15 [14-17] & 16 [15-20] & 0.065 \\
\hline$V_{T}, \mathrm{ml} / \mathrm{kg} \mid \mathrm{BW}$ & $7.3[6.7-7.3]$ & $8.0[7.0-8.9]$ & 0.098 & $7.2[6.4-8.0]$ & $7.3[6.1-7.9]$ & 0.673 \\
\hline Ppeak, $\mathrm{CmH}_{2} \mathrm{O}$ & 20 [17-24] & $27[24-31]$ & $<0.0001$ & 21 [17-25] & 29 [22-33] & $<0.0001$ \\
\hline Pplat, $\mathrm{cmH}_{2} \mathrm{O}$ & 17 [15-19] & 19 [16-18] & 0.009 & 17 [15-20] & 19 [15-21] & 0.227 \\
\hline$\Delta P, \mathrm{cmH}_{2} \mathrm{O}$ & 9 [8-12] & $11[8-13]$ & 0.268 & 9 [8-12] & $9[7-12]$ & 0.741 \\
\hline
\end{tabular}

EFL expiratory flow limitation, Cst,rs static compliance of the respiratory system, Rrs,max total resistance of the respiratory system, Rrs,min flow resistance of the respiratory system, $\triangle R r$ s additional resistance of the respiratory system, $P / F$ arterial partial oxygen pressure to fraction of inspired oxygen ratio, $P E E P i$ intrinsic positive end-expiratory pressure, $P E E P$ appl positive end-expiratory pressure applied at the ventilator, $R R$ respiratory rate, $V_{T}$ tidal volume, $I B W$ ideal body weight, Ppeak peak inspiratory pressure, $P$ plat plateau pressure, $\Delta P$ driving pressure 


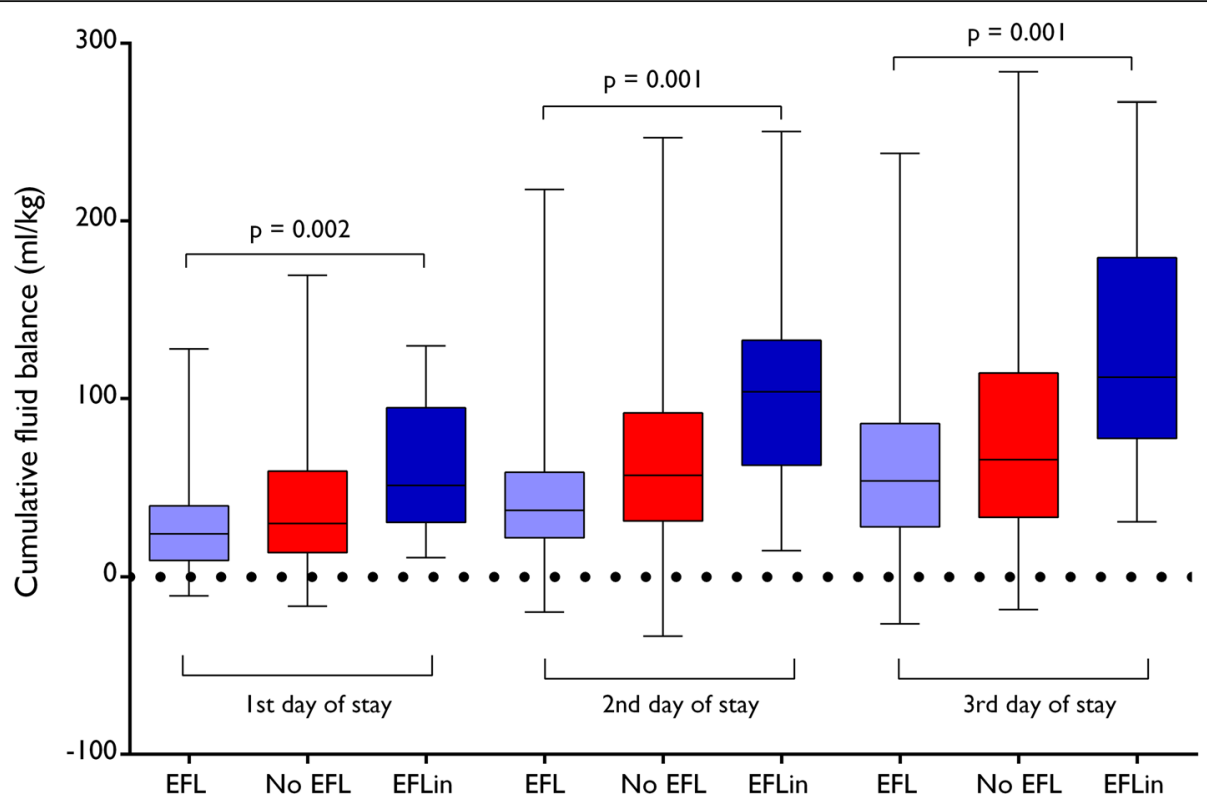

Fig. 2 Cumulative fluid balance over the first 3 days of ICU stay. Patients who developed expiratory flow limitation (EFL) after ICU admission (blue) had higher cumulative fluid balances compared to those flow limited at admission (violet), and those who never developed EFL (red)

have relevant clinical consequences since the presence of EFL has numerous side effects [1], such as the presence of PEEPi [32] that might have detrimental effects on respiratory efficiency and cardiovascular function. Further, the reduction of the expiratory flow and the inability to increase it by the expiratory muscle contraction decrease the efficacy of cough and secretion removal [14] favouring the development of atelectasis, bronchitis and pneumonia. Finally, EFL might imply cyclic opening/closure of the small airways $[7,33]$ that can lead to hypoxaemia and ventilation/perfusion mismatch.

Interestingly, a large amount of the patients enrolled in the present study (48\%) were flow limited within the first $72 \mathrm{~h}$ of ICU stay, suggesting that EFL is common in ICU patients. Patients with EFL had higher duration of mechanical ventilation, ICU length of stay and ICU mortality. These outcomes were associated with a more compromised respiratory function since these patients

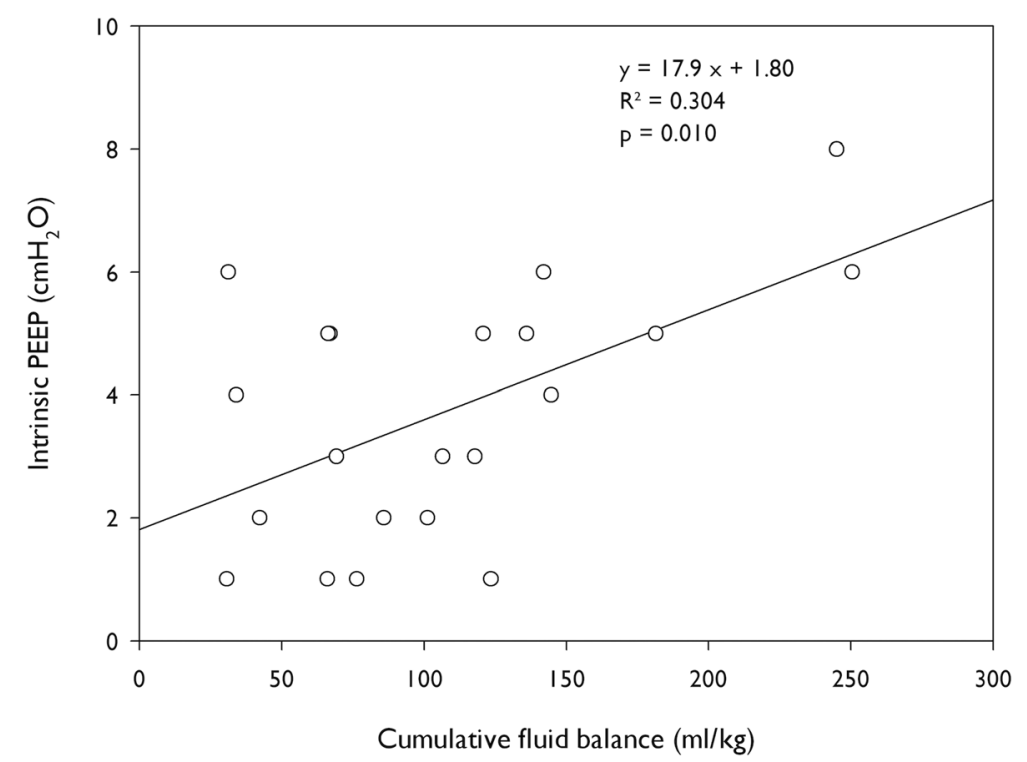

Fig. 3 Correlation between CFB and values of PEEPi in patients developing EFL after the ICU admission. The correlation was determined the day the patients became flow limited 
Table 4 Association between severe cumulative fluid overload and development of expiratory flow limitation according to univariate logistic regression analysis

\begin{tabular}{llll}
\hline Variables & Crude odds ratio & $95 \% \mathrm{Cl}$ & $p$ value \\
\hline CFO $\geq 10 \%$ & & & \\
$\quad$ 1st to 2nd ICU day of stay & 3.9 & $1.4-10.9$ & 0.011 \\
CFO $\geq 10 \%$ & & & \\
$\quad$ 1st to 3rd ICU day of stay & 3.1 & $1.1-8.5$ & 0.030 \\
AKI in ICU & 2.2 & $0.8-6.0$ & 0.796 \\
AHRF & 0.2 & $0.1-1.2$ & 0.075 \\
ARDS & 0.9 & $0.2-3.6$ & 0.862 \\
Septic shock & 2.5 & $0.9-6.8$ & 0.077 \\
\hline
\end{tabular}

CFO cumulative fluid overload, AKI acute kidney injury, ICU intensive care unit, $A H R F$ acute hypoxaemic respiratory failure, $A R D S$ acute respiratory distress syndrome

exhibited increased inspiratory and additional resistance and higher PEEPi.

However, our study shows another complementary aspect that deserves clinical attention. We were surprised that 21 patients $(17 \%)$ became flow limited after ICU admission. While it is easily explainable that obese patients or those with COPD or heart disease can exhibit EFL at ICU admission, it could be less clear why patients might develop EFL during the ICU stay. Interestingly, the main determinant of EFL after ICU admission was a positive fluid balance. Patients who developed EFL during the first $72 \mathrm{~h}$ of ICU stay had the higher cumulative fluid overload (Table 4 and Fig. 2); further, a CFO $\geq 10 \%$ over the first 2 days of ICU stay was independently associated with EFL (OR 3.7, 95\%CI 1.2-11.4, $p=0.025$ ).

Hence, fluid therapy can have relevant clinical consequences even at the lung level. Physician should pay particular attention to the amount of fluid administered. Excessive fluids administration can lead to EFL. The latter has been demonstrated to be responsible of damage of small airways that elicit an inflammatory response $[22,23]$. It was previously demonstrated that a positive fluid balance can worsen respiratory function, increase the occurrence of pulmonary complication and have an impact on patients' outcome in patients with acute lung injury and ARDS [34-36].

Detecting and abolishing EFL should be part of the lung-protective strategy. Ventilation at low lung volume leading to EFL could be avoided by the use of PEEP. In patients with flow limited at the ICU admission, the value of PEEP able to avoid EFL was 8 [6-10] $\mathrm{cmH}_{2} \mathrm{O}$ and then statistically decreased to 6 [5-8] at day 3, while in those developing EFL during the ICU stay, this value was 5 [5-6] $\mathrm{cmH}_{2} \mathrm{O}$ at day 1 and 5 [4-7] at day 3. The effects of PEEP on EFL have been previously tested in patients with ARDS. Koutsoukou et al. [37] demonstrated that $10 \mathrm{cmH}_{2} \mathrm{O}$ of PEEP abolished the presence of EFL during tidal ventilation. The difference between the two studies could be the patients' population, the severity of the underlying disease and the number of patients enrolled. Koutsoukou et al. [37] studied 13 patients while we enrolled 121 patients with ARF of different aetiologies.

The present study has some limitations: (1) it is a single-centre design with limited sample size. However, this is the first study aiming at identifying possible causes of EFL occurrence in an unselected cohort of ventilated patients; (2) we did not use other techniques such as extra-vascular lung water measurement or lung ultrasound to quantify lung oedema for confirming the association between cumulative fluid overload and EFL occurrence; (3) application of the PEEP test, as it is for all tests evaluating the presence of EFL, carries the need of having the patients for one breath at ZEEP. This could partially derecruit the lung, although the limited time on ZEEP ventilation should minimise the possible effects of the PEEP test on lung function; and (4) we have reported some data on the association between EFL prevalence/development and ICU mortality. However, these data should be regarded only as descriptive since the observational nature of this study and the small sample size do not allow us to make any conclusion. Future larger studies are needed to prove the potential effect of EFL development on the increase of ICU mortality.

\section{Conclusions}

The presence of EFL is common among ICU patients requiring mechanical ventilation for acute respiratory failure of different aetiologies. Interestingly, the major determinant for developing EFL in patients during the first 3 days of their ICU stay is a positive fluid balance. Further studies are needed to assess if a restrictive fluid therapy might be associated with a lower incidence of EFL.

\section{Supplementary information}

Supplementary information accompanies this paper at https://doi.org/10. 1186/s13054-019-2682-4.

Additional file 1. Flow chart of the study

Additional file 2. Flow-volume loops during positive end-expiratory pressure (PEEP) test

Additional file 3. Clinical and Demographic Characteristics of the Patients Enrolled grouped according to the absence / presence of EFL Additional file 4. "PEEP-EFL" values calculated according to the PEEP test in patients with EFL.

Additional file 5. Respiratory mechanics characteristic of the patients who developed EFL during the ICU stay.

Additional file 6. Cumulative fluid balance and cumulative fluid overload over the first 3 days of ICU stay.

\section{Abbreviations}

AHRF: Acute hypoxaemic respiratory failure; AKl: Acute kidney injury; ARDS: Acute respiratory distress syndrome; BMI: Body mass index; 
CFB: Cumulative fluid balance; CFO: Cumulative fluid overload; CKD: Chronic kidney disease; Cl: Confidence interval; COPD: Chronic obstructive pulmonary disease; Cst,rs: Static compliance of the respiratory system; $\Delta \mathrm{P}$ : Driving pressure; $\Delta$ Rrs: Additional resistance of the respiratory system; EFL: Expiratory flow limitation; EPP: Equal pressure point; KDIGO: Kidney Disease Improving Global Outcomes; IBW: Ideal body weight; ICU: Intensive care unit; MRC: Modified Medical Research Council; NYHA: New York Heart Association classification; OR: Odds ratio; OSAS: Obstructive sleep apnoea syndrome; PEEP: Positive end-expiratory pressure; PEEPappl: Positive end-expiratory pressure applied at the ventilator; PEEPi: Intrinsic positive end-expiratory-pressure: P/F: Arterial partial oxygen pressure to fraction of inspired oxygen ratio; Ppeak: Peak inspiratory pressure; Pplat: Plateau pressure; RR: Respiratory rate; Rrs,max: Total resistance of the respiratory system; Rrs,min: Flow resistance of the respiratory system; SAPS: Simplified Acute Physiology Score; SOFA: Sequential Organ Failure Assessment; $\mathrm{V}_{\mathrm{T}}$ : Tidal volume; ZEEP: ZeroPEEP

\section{Acknowledgements}

We would both like to thank all of the nursing and medical staff on the ICU at Sant'Anna Hospital, Ferrara, Italy.

\section{Authors' contributions}

CAV, EM and SS contributed to design the conception and design of the study. FDC, CR, AF and GS participated in the acquisition and analysis of data for the study. CAV, FDC and SS drafted the work. DLG and RR contributed to the data interpretation and were involved in drafting and revising the manuscript. All authors collaborated to interpret data, revise the work critically for important intellectual content and approve the final version of the manuscript.

\section{Funding}

None

\section{Availability of data and materials}

The datasets used and/or analysed during the current study are available from the corresponding author on reasonable request.

\section{Ethics approval and consent to participate}

The study was approved by the ethics committee of our institution (Azienda Ospedaliero-Universitaria Ferrara Ethic Committee, protocol number: 74/ 2016). Informed consent was obtained from each patient or next of kin.

\section{Consent for publication}

Not applicable.

\section{Competing interests}

The authors declare that they have no competing interests.

\section{Author details}

'Department of Morphology, Surgery and Experimental Medicine, Azienda Ospedaliera-Universitaria Arcispedale Sant'Anna, University of Ferrara, Via Aldo Moro, 8, 44124 Ferrara, Italy. ${ }^{2}$ Department of Anesthesiology and Intensive Care Medicine, Catholic University of The Sacred Heart, Milan, Italy. ${ }^{3}$ Department of Anesthesia and Intensive Care Unit, ASST Fatebenefratelli Sacco, Luigi Sacco Hospital, Polo Universitario, University of Milan, Milan, Italy.

\section{Received: 13 September 2019 Accepted: 21 November 2019}

\section{Published online: 05 December 2019}

\section{References}

1. Junhasavasdikul D, Telias I, Grieco DL, et al. Expiratory flow limitation during mechanical ventilation. Chest. 2018;154:948-62.

2. Mead J, Turner JM, Macklem PT, et al. Significance of the relationship between lung recoil and maximum expiratory flow. J Appl Physiol. 1967;22: 95-108

3. Hyatt RE. Expiratory flow limitation. J Appl Physiol Respir Environ Exerc Physiol. 1983;55:1-7.

4. Eltayara L, Becklake MR, Volta CA, et al. Relationship between chronic dyspnea and expiratory flow limitation in patients with chronic obstructive pulmonary disease. Am J Respir Crit Care Med. 1996:154:1726-34.

5. OF P, Butler JP. Expiratory flow limitation. Compr Physiol. 2011;1:1861-82.
6. Koulouris NG, Dimopoulou I, Valta P, Finkelstein R, Cosio MG, Milic-Emili J. Detection of expiratory flow limitation during exercise in COPD patients. Appl Physiol (1985). 1997;82:723-31.

7. Koutsoukou A, Pecchiari M. Expiratory flow-limitation in mechanically ventilated patients: a risk for ventilator-induced lung injury? World J Crit Care Med. 2019:8:1-8.

8. Alvisi V, Romanello A, Badet M, et al. Time course of expiratory flow limitation in COPD patients during acute respiratory failure requiring mechanical ventilation. Chest. 2003:123:1625-32.

9. Koutsoukou A, Armaganidis A, Stavrakaki-Kallergi C, et al. Expiratory flow limitation and intrinsic positive end-expiratory pressure at zero positive endexpiratory pressure in patients with adult respiratory distress syndrome. Am J Respir Crit Care Med. 2000:161:1590-6.

10. Chen L, Del Sorbo L, Grieco DL, et al. Airway closure in acute respiratory distress syndrome: an underestimated and misinterpreted phenomenon. Am J Respir Crit Care Med. 2018;197:132-6.

11. Duguet $A$, Tantucci $C$, Lozinguez $O$, et al. Expiratory flow limitation as a determinant of orthopnea in acute left heart failure. J Am Coll Cardiol. 2000; 35:690-700.

12. Torchio R, Gulotta C, Greco-Lucchina P, et al. Orthopnea and tidal expiratory flow limitation in chronic heart failure. Chest. 2006:130:472-9.

13. Goetghebeur D, Sarni D, Grossi Y, et al. Tidal expiratory flow limitation and chronic dyspnoea in patients with cystic fibrosis. Eur Respir J. 2002;19:492-8.

14. Alvisi V, Marangoni E, Zannoli S, et al. Pulmonary function and expiratory flow limitation in acute cervical spinal cord injury. Arch Phys Med Rehabil. 2012:93:1950-6.

15. Koutsoukou A, Koulouris N, Bekos B, et al. Expiratory flow limitation in morbidly obese postoperative mechanically ventilated patients. Acta Anaesthesiol Scand. 2004;48:1080-8.

16. Spadaro S, Caramori G, Rizzuto C, et al. Expiratory flow limitation as a risk factor for pulmonary complications after major abdominal surgery. Anesth Analg. 2017:124:524-30.

17. Guérin C, Coussa ML, Eissa NT, Corbeil C, Chassé M, Braidy J, Matar N, MilicEmili J. Lung and chest wall mechanics in mechanically ventilated COPD patients. J Appl Physiol (1985). 1993;74:1570-80.

18. Armaganidis A, Stavrakaki-Kallergi K, Koutsoukou A et al. Intrinsic positive end-expiratory pressure in mechanically ventilated patients with and without tidal expiratory flow limitation. Crit Care Med. 2000:28:3837-42.

19. Yonis $H$, Mortaza $S$, Baboi $L$, et al. Expiratory flow limitation assessment in patients with acute respiratory distress syndrome. A reappraisal. Am J Respir Crit Care Med. 2018;198:131-4

20. Marangoni E, Alvisi V, Ragazzi R, et al. Respiratory mechanics at different PEEP level during general anesthesia in the elderly: a pilot study. Minerva Anestesiol. 2012;78:1205-14.

21. Muscedere JG, Mullen JB, Gan K, et al. Tidal ventilation at low airway pressures can augment lung injury. Am J Respir Crit Care Med 1994; 149: 1327-1334

22. D'Angelo E, Pecchiari M, Baraggia $P$, et al. Low volume ventilation causes peripheral airway injury and increased airway resistance in normal rabbits. J Appl Physiol (1985). 2002;92:949-56

23. Pecchiari M, Monaco A, Koutsoukou A, Della Valle P, Gentile G, D'Angelo E. Effects of various modes of mechanical ventilation in normal rats. Anesthesiology. 2014;120:943-50.

24. Koutsoukou A. Expiratory flow limitation and airway closure in patients with acute respiratory distress syndrome. Am J Respir Crit Care Med. 2019;199: $127-8$.

25. Mahler DA, Wells CK. Evaluation of clinical methods for rating dyspnea. Chest. 1998;93:580-6.

26. Society AT, Society ER. Diagnosis and management of stable chronic obstructive pulmonary disease: a clinical practice guideline update from the American College of Physicians, American College of Chest Physicians, American Thoracic Society, and European Respiratory Society. Ann Intern Med. 2011;155:179-91

27. Global Initiative for Chronic Obstructive Lung Disease (GOLD). Global strategy for the diagnosis, management, and prevention of chronic obstructive pulmonary disease. 2018 [internet publication]

28. ARDS Definition Task Force. Acute respiratory distress syndrome: the Berlin Definition. JAMA. 2012:307:2526-33.

29. KDIGO AKI. Guideline Work Group. Diagnosis, evaluation, and management of acute kidney injury: a KDIGO summary (part 1). Crit Care. 2013;17:204 
30. Singer M, Deutschman CS, Seymour CW, et al. The third international consensus definitions for sepsis and septic shock (Sepsis-3). JAMA. 2016;315 801-10.

31. Samoni S, Vigo V, Reséndiz LI, et al. Impact of hyperhydration on the mortality risk in critically ill patients admitted in intensive care units: comparison between bioelectrical impedance vector analysis and cumulative fluid balance recording. Crit Care. 2016;20:95.

32. VENTILAB group. Effect of external PEEP in patients under controlled mechanical ventilation with an auto-PEEP of $5 \mathrm{cmH}_{2} \mathrm{O}$ or higher. Ann Intensive Care. 2016;6:53.

33. Valta P, Corbeil C, Lavoie A, et al. Detection of expiratory flow limitation during mechanical ventilation. Am J Respir Crit Care Med. 1994;150:1311-7.

34. Pediatric Acute Lung Injury and Sepsis Investigator's (PALISI) Network; Acute Respiratory Distress Syndrome Clinical Research Network (ARDSNet). Fluid balance in critically ill children with acute lung injury. Crit Care Med. 2012; 40:2883-9.

35. Sepsis Occurrence in Acutely III Patients Investigators. High tidal volume and positive fluid balance are associated with worse outcome in acute lung injury. Chest. 2005;128:3098-108.

36. National Heart, Lung, and Blood Institute Acute Respiratory Distress Syndrome (ARDS) Clinical Trials Network. Comparison of two fluid-management strategies in acute lung injury. N Engl J Med. 2006;354:2564-75.

37. Koutsoukou A, Bekos B, Sotiropoulou C, et al. Effects of positive endexpiratory pressure on gas exchange and expiratory flow limitation in adult respiratory distress syndrome. Crit Care Med. 2002;30:1941-9.

\section{Publisher's Note}

Springer Nature remains neutral with regard to jurisdictional claims in published maps and institutional affiliations.

Ready to submit your research? Choose BMC and benefit from:

- fast, convenient online submission

- thorough peer review by experienced researchers in your field

- rapid publication on acceptance

- support for research data, including large and complex data types

- gold Open Access which fosters wider collaboration and increased citations

- maximum visibility for your research: over $100 \mathrm{M}$ website views per year

At BMC, research is always in progress.

Learn more biomedcentral.com/submissions 